\title{
Development of Optical Chemical Sensor Based on Pararosaniline in Sol-Gel Matrix for Detection of Formaldehyde in Food Samples
}

\author{
Agus Abdul Gani ${ }^{1}$, Mochammad Yuwono ${ }^{2}$, Bambang Kuswandi ${ }^{1}$ \\ ${ }^{1}$ Chemo and Biosensors Group, Faculty of Pharmacy, Jember University, Jember, Indonesia \\ ${ }^{2}$ Faculty of Pharmacy, Airlangga University, Surabaya, Indonesia \\ Email: Agusagani@yahoo.com
}

Received September 29, 2013; revised November 1, 2013; accepted November 18, 2013

Copyright (C) 2013 Agus Abdul Gani et al. This is an open access article distributed under the Creative Commons Attribution License, which permits unrestricted use, distribution, and reproduction in any medium, provided the original work is properly cited.

\begin{abstract}
Optical chemical sensor based on immobilesed pararosaniline into sol-gel matrix tetraethyl orthosilicate (TEOS) is a simple tool that can be used to detect the presence of formalin (formaldehide) in food. Pararosaline in sol-gel matrix was developed when contacted with food sample that contains formalin. The optical signal was produced by changing color from purple to yellow, that can be used to detect quantitative formaldehide in sample. The results, chemo sensor optic, have characteristic, maximum wave length $576.42 \mathrm{~nm}$, with linier range $0-100 \mathrm{ppm}$, linearity coefficient $\mathrm{R}^{2}=$ 0.999 , limit detection (LOD) $0.504 \mathrm{ppm}$, limit of quantification (LOQ) $1.680 \mathrm{ppm}$, sensitivity 0.087 , disturbed matrix selectivity $1.716 \%$. The optimum is operational at $\mathrm{pH} 4$, and response time at 150 seconds of 2 ppm. This sensor can be used to detect formalin in food sample in a simple mode and reusable for 4 times application. In addition, the sensor can be regenerated using an acid $0.1 \mathrm{M} \mathrm{HCl}$.
\end{abstract}

Keywords: Optical Chemical Sensor; Formaldehide; Pararosalin; Sol-Gel; Food Sample

\section{Introduction}

Some of food in public marketed discovered contains formaldehyde or usually familiar formaldehyde [1]. Formaldehyde is a very dangerous chemical in human health; It gives negative effect to respiration channel, liver and kidney function, and reproducing system [2,3]. Based on the moment conditions, detecting process of formaldehyde in food, conducting by laboratory process, used GC, HPLC and spectrometry instrument. The weakness methods of the mentioned impracticably cannot be prepared out of laboratory and need skilled persons who have backgrounds in chemistry specialty. In addition, such methods are not suitable to be employed in the fields [4]. Therefore, there is an acute need to develop new and inexpensive methods of assessing the formaldehyde contain in food, particularly those that can be employed in the field. The alternative methods to detecting formaldehyde in food have simple process, low cost, and easy to operate by general society $[5,6]$.

In this respect, the chemical sensor represents tools used for simple, quick and low-cost to detect of formal- dehyde in food [7-11]. Developing simple specific optical sensor of formaldehyde is very urgent to give solutions to problems in general public to detect formaldehyde contained in food. The detection of formal-dehyde in food has been proposed using spectrometric [7,11]. Pararosaniline is one of the specific reagents to detect formaldehyde, and the reaction between pararosaniline and formaldehyde is presented in Figure 1, next page [5,12].

The optical chemical sensor developing is based on reagent immobilizing to sol-gel system. Optical transducers in particular have raised much interest currently [12-15]. Since, various novel materials can be used in optical sensors such as zeolite, conducting polymers, sol-gel etc. [79].

Sol-gel for instance, there are many advantages, such as its optical clarity, the ability to entrap specific reagent, thermal and chemical stability, simplicity of preparation and flexibility in controlling its pore size and geometry $[11,13]$.

This research uses Tetra Ethyl Ortho Silicate (TEOS) as sol-gel material and shaping as sol-gel granule. The mechanism process, formaldehyde in solution system of 


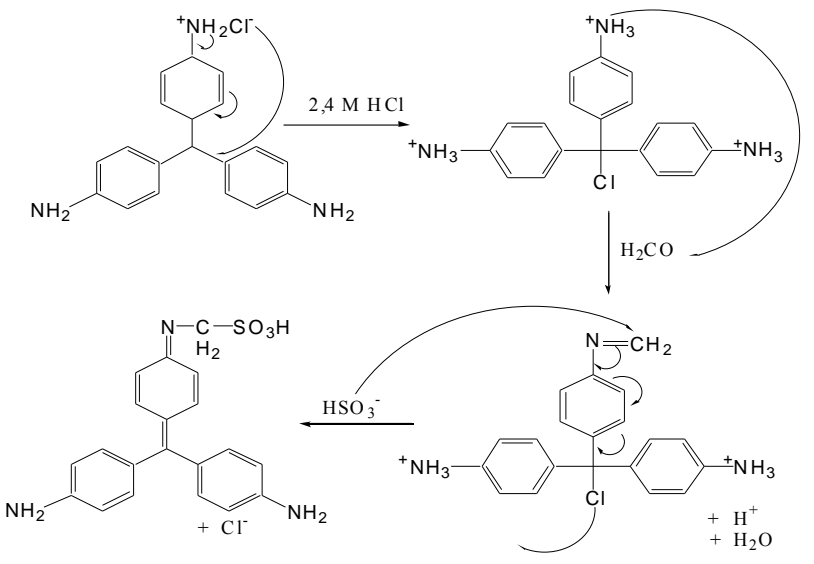

Figure 1. Formaldehyde-pararosaniline reaction.

diluting food, diffuses sol-gel and reacts with pararosaniline reagent producing change color of sol-gel [12]. The specific colors changed sol-gel from yellow to violet indicating that food solution contains formaldehyde, so the food has been solute contains formaldehyde. The solgel optical sensor can be used to detect formaldehyde contains in food as qualitative and quantitative manner.

\section{Experimental}

\subsection{Reagent}

All reagents were used as purchased without further purification. Pararosaniline hydrochloride (SIGMA P3750) was supplied from Sigma (UK). Tetra ethyl orthosilicate (TEOS), hydrochloric acid ( $\mathrm{HCl} 37 \%$ pa), Ethanol 96\%, Triton $\mathrm{X}-100$, and sodium sulfite $\left(\mathrm{Na}_{2} \mathrm{SO}_{3}\right)$ as precursor of sol-gel, were obtained from BDH-Merck (UK). For immobilization a phosphate buffer solution (PBS) with $\mathrm{pH}$ 6,5 was prepared by adjusting amounts of $\mathrm{NaCl}, \mathrm{KCl}$, $\mathrm{Na}_{2} \mathrm{HPO}_{4}$ and $\mathrm{KH}_{2} \mathrm{PO}_{4}$ buffer systems; in all cases, the mixture were $0.1 \mathrm{M}$ in each constituent. The standard formaldehyde solutions of $(2 ; 6 ; 10 ; 20 ; 100 ; 200 ; 300$; 400; 500) ppm (grade of analytical, Merck) were prepared by appropriate dilution with an appropriate buffer solution in order to produce solutions of lower concentration at a desired $\mathrm{pH}$. Salt and sugar use as interference material. All reagents and inorganic salts were of analytical grade and made using double distillate water.

\subsection{Reagent Immobilizations}

Pararosaniline reagent prepared by making solution, take of $0.03 \mathrm{~g}$ pararosaniline hydrochloride, diluting by water to total volume $10 \mathrm{~mL}$ used volumetric flask, this solution concentration is $3000 \mathrm{ppm}$. The solution on $\mathrm{Na}_{2} \mathrm{SO}_{3}$, made of $0.1 \mathrm{~g} \mathrm{Na}_{2} \mathrm{SO}_{3}$ diluting by water to total volume $10 \mathrm{~mL}$ used volumetric flask. Pararosaniline sol-gel made by composing of $1.5 \mathrm{~mL}$ pararosaniline reagent,

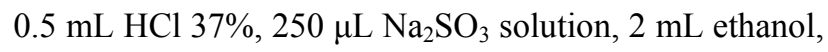
$1.75 \mathrm{~mL}$ water, and $4.5 \mathrm{~mL}$ TEOS composing in beaker glass, stirring a long 3 - 5 hours. After that adding 5 drops of triton X-100 and stirring again 30 minutes, after that molding sol-gel as sol-gel.

\subsection{Optical Fiber Biosensors Construction}

The construction of the optical fiber sol-gel chemo sensor has been carried out by carefully placed a single sol-gel of pararosaniline into the specially designed flowcell (Figure 2). This flow-cell $(15 \times 10 \mathrm{~mm}$ and $15 \mathrm{~mm}$ depth) has been designed as back pressure free flow cell, so that the effect of pulse from the pump and air bubbles could be removed. Since these problems often faced in flow system, which in turn increasing noise in signal response. This optical chemical sensor design also allows reducing the effect of other incident light levels on the flow-cell and optical system.

\subsection{Results and Discussion}

\subsubsection{Sol-Gel Sensor Product.}

The sol-gel sensor product fabrication and it color change before to after interaction with formaldehyde presenting as Figure 3 .

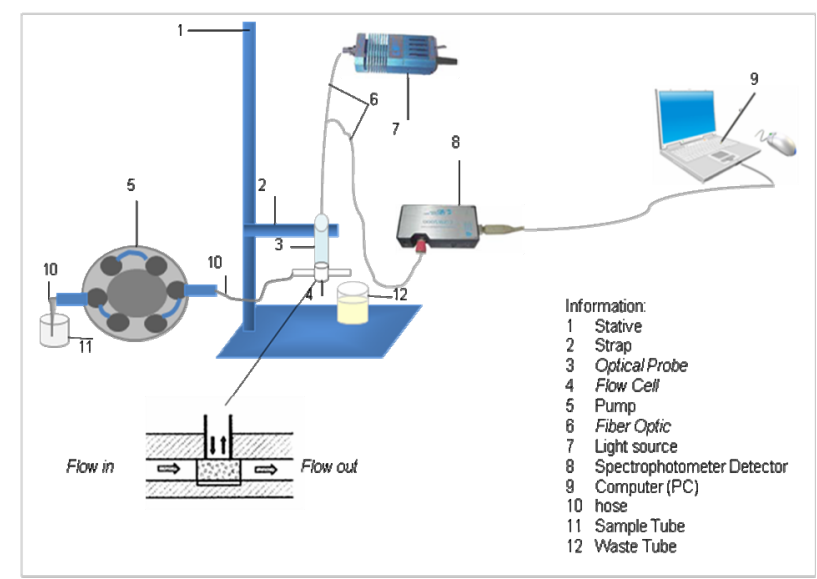

Figure 2. Flow-cell for optical fiber chemical sensor.

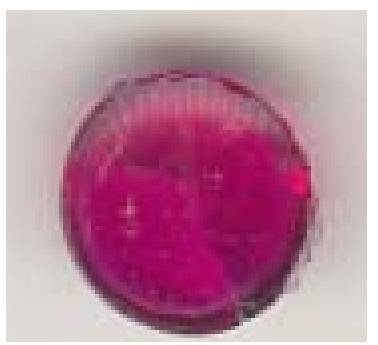

(a)

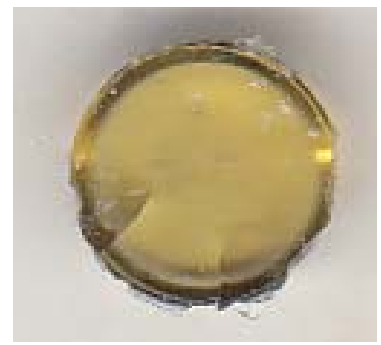

(b)
Figure 3. Shape and color change of chemical sensor.(a): Chemical sensor before interaction with formalin; (b): Chemical sensor after interaction with formalin. 


\subsubsection{Optimization of Experimental Parameters}

1) Optimum Wave Length Operational and Linearity Range Concentration

The first step in parameter optimization is to finding the optimal wave length, base on the scanning the spectra of blank solution and some standard formaldehyde solution, 2 ppm, 10 ppm, 20 ppm, 100 ppm, 200 ppm, 800 $\mathrm{ppm}$ and $1000 \mathrm{ppm}$. Result of scanning as presenting by Figure 4, from this spectra, have been result the optimum wave length base on the correlation between standard formaldehyde concentrations with intensity of reflectance produced by sol-gel sensor after reacted with formaldehyde in solution.

Based on Figure 4, it is able to resume the reflectance intensity as Table 1 follows.

Base on Table 1, the optimum wave length operational is $576.42 \mathrm{~nm}$, and the linearity range concentration (0 $100) \mathrm{ppm}$, has slope or sensitivity 0.087 , intercept 10.310 , and linierity coefficient $\mathrm{R}^{2}=0.999[15,16]$.

2) Test the Confidence Level Linearity

Linearity test includes a margin of error sensitivity (slope error) and the margin of error intercept (intercept error). The results of calculations with a $95 \%$ of confidence level obtained error bounds of sensitivity $0.087 \pm$ 0.0003 and a margin error of intercept $10.31 \pm 0.0109$ $[10,16]$.

3) Limit of Detection (LOD) and Limit of Quantification (LOQ)

Referring to Figure 4 and Table 1 further tested the linearity of the calibration curve in detail for the concentration range of $0 \mathrm{ppm}$ to $100 \mathrm{ppm}$, with measurements repeated 7 times for each standard solution. The concentration of the standard solution used is a concentration of 0 ppm, 2 ppm, 4 ppm, 6 ppm, 8 ppm, 10 ppm, 12 ppm, $14 \mathrm{ppm}, 16 \mathrm{ppm}, 18 \mathrm{ppm}, 20 \mathrm{ppm}, 40 \mathrm{ppm}, 60 \mathrm{ppm}, 80$ $\mathrm{ppm}$ and $100 \mathrm{ppm}$. The next linearity test based on the average concentration measurements every standard. The test results give the following data as Table 2 and Figure 5.

Based on data from the linearity of the curve in Table 2 and Figure 5, it obtained the limit of detection (LOD) worth $0.5041 \mathrm{ppm}$ and limit of quantitation (LOQ) of $1.6804 \mathrm{ppm}[16]$.

4) Sensor Reproducibility

The data resumes to detecting Sensor Repro-ductivebility Measurement from 7 repeatbles as presenting Table 3 followed. Table 3 data give reality, the variance coefficient measurements base of reflectance signal, minimum $0.025 \%$ and optimum $0.557 \%$. The variance coefficient measurements base of formalin contains, minimum $0.8768 \%$ and optimum $4.7875 \%$. This condition are lowest of $5 \%$, so the chemical sensor is usable as formalin detector $[10,16]$.

5) Sensor Responses Time

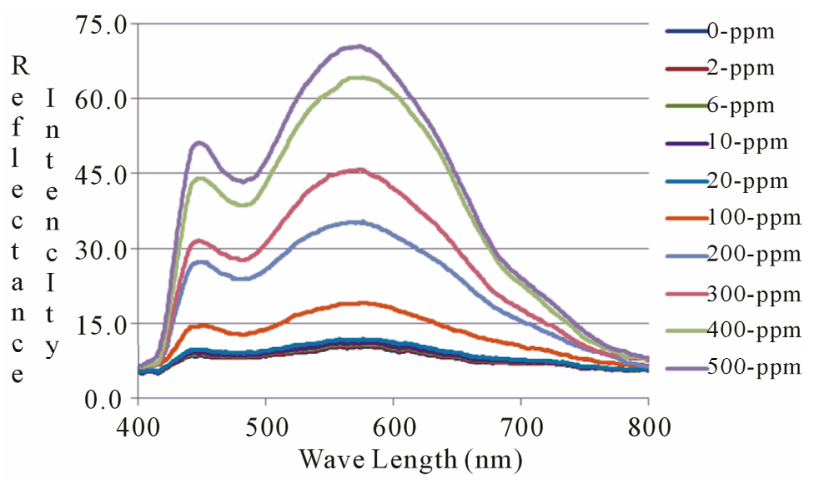

Figure 4. Spectra profile of formaldehyde by pararosaline TEOS optical chemical sensor.

Table 1. The optimum reflectance intensity some standard formadehyde solution.

\begin{tabular}{ccccccccc}
\hline $\begin{array}{c}\left.\mathrm{H}_{2} \mathrm{CO}\right] \\
(\mathrm{ppm})\end{array}$ & \multicolumn{2}{c}{ Left peaks } & \multicolumn{2}{c}{ Right peaks } & \multicolumn{3}{c}{$\lambda$ Tested } \\
\hline 0 & 448.26 & 8.538 & 576.42 & 10.377 & 8.456 & 8.538 & 10.377 \\
2 & 444.42 & 8.653 & 576.42 & 10.547 & 8.429 & 8.511 & 10.547 \\
6 & 446.82 & 8.882 & 576.42 & 10.888 & 8.871 & 8.830 & 10.888 \\
10 & 442.5 & 9.112 & 576.42 & 11.228 & 8.907 & 8.995 & 11.228 \\
20 & 447.30 & 9.685 & 576.42 & 11.867 & 9.685 & 9.627 & 11.867 \\
100 & 453.06 & 14.551 & 576.42 & 18.989 & 14.284 & 14.443 & 18.989 \\
200 & 448.26 & 27.294 & 576.42 & 35.354 & 27.245 & 27.294 & 35.354 \\
300 & 447.30 & 31.518 & 574.98 & 45.763 & 31.518 & 31.438 & 45.634 \\
400 & 447.30 & 44.015 & 574.94 & 64.237 & 44.015 & 43.976 & 61.213 \\
500 & 448.26 & 51.101 & 574.02 & 70.497 & 50.405 & 51.101 & 70.249 \\
\hline
\end{tabular}

Table 2. Reflectance intensity data of linierity curve 0 ppm $100 \mathrm{ppm}$ on $576.42 \mathrm{~nm}$.

\begin{tabular}{cccc}
\hline [Formalin] & Measuring Intensity $(\mathrm{Y})$ Kurve Intensity $(\hat{\mathrm{Y}})$ & $(\mathrm{Y}-\hat{\mathrm{Y}})^{2}$ \\
\hline 0 & 10.328 & 10.310 & 0.00034 \\
2 & 10.504 & 10.484 & 0.00040 \\
4 & 10.669 & 10.658 & 0.00013 \\
6 & 10.845 & 10.832 & 0.00017 \\
8 & 11.026 & 11.006 & 0.00039 \\
10 & 11.191 & 11.180 & 0.00013 \\
12 & 11.348 & 11.354 & 0.00003 \\
14 & 11.520 & 11.528 & 0.00007 \\
16 & 11.693 & 11.702 & 0.00008 \\
18 & 11.859 & 11.876 & 0.00028 \\
20 & 12.037 & 12.050 & 0.00018 \\
40 & 13.802 & 13.790 & 0.00014 \\
60 & 15.539 & 15.530 & 0.00009 \\
80 & 17.287 & 17.270 & 0.00028 \\
100 & 19.019 & 19.010 & 0.00008 \\
\multicolumn{2}{c}{ Deviasion } & Standard & \multicolumn{2}{c}{0.01462} & \\
\hline
\end{tabular}




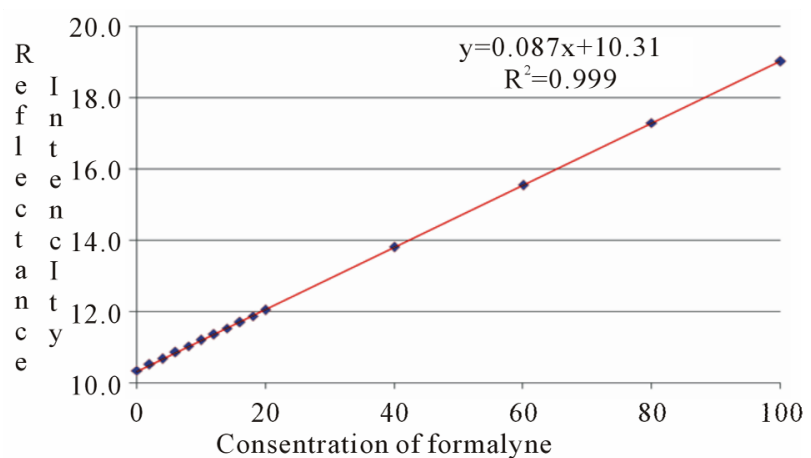

Figure 5. Test product of linearity on concentration range of 0 ppm - 100 ppm, on wave length $576.42 \mathrm{~nm}$, by 7 time repetition for each standard solution.

Table 3. Data of reproducibility measurements.

\begin{tabular}{ccccccc}
\hline & \multicolumn{3}{c}{ Sensor Reflectance } & \multicolumn{3}{c}{ Measurement Concentration } \\
\cline { 3 - 7 } \begin{tabular}{c}
$\mathbf{C H}_{\mathbf{2}} \mathbf{O} \mathbf{p p m}$ \\
\cline { 3 - 7 }
\end{tabular} & Averg. & STDev & \% KV & $\begin{array}{c}\text { Averg. } \\
\text { (ppm) }\end{array}$ & STDev & \% KV \\
\hline 0 & 10.328 & 0.015 & 0.142 & 0.948 & 0.0126 & 1.3240 \\
2 & 10.504 & 0.003 & 0.025 & 2.355 & 0.0297 & 1.2598 \\
4 & 10.669 & 0.017 & 0,160 & 4.361 & 0.1958 & 4.4902 \\
6 & 10.845 & 0.022 & 0.200 & 6.784 & 0.2498 & 3.6826 \\
8 & 11.026 & 0.022 & 0.197 & 8.617 & 0.2494 & 2.8939 \\
10 & 11.191 & 0.039 & 0.347 & 10.125 & 0.4457 & 4.4017 \\
12 & 11.348 & 0.038 & 0.331 & 11.358 & 0.4315 & 3.7992 \\
14 & 11.520 & 0.041 & 0.355 & 13.208 & 0.4677 & 3.5411 \\
16 & 11.693 & 0.062 & 0.530 & 14.865 & 0.7117 & 4.7875 \\
18 & 11.859 & 0.030 & 0.249 & 16.832 & 0.3387 & 2.0122 \\
20 & 12.037 & 0.066 & 0.551 & 19.847 & 0.7619 & 3.8390 \\
40 & 13.802 & 0.077 & 0.557 & 41.860 & 0.8829 & 2.1092 \\
60 & 15.539 & 0.047 & 0,302 & 61.426 & 0.5386 & 0.8768 \\
80 & 17.287 & 0.086 & 0.495 & 80.996 & 0.9828 & 1.2134 \\
100 & 19.019 & 0.045 & 0.238 & 100.564 & 0.5194 & 0.5164 \\
\hline
\end{tabular}

The responses time of sensor has been affected by concentration of formaldehyde in solution system. Type of formaldehyde concentration affected to sensor response time presenting like Figure 6, follow. Base on Figure 6, the response time of sensor between 75.88 seconds for $500 \mathrm{ppm}$ to 150 seconds for $2 \mathrm{ppm}$ formaldehyde concentrations.

6) Operational Conditions of $\mathrm{pH}$ Sensor

The reaction between pararosaniline with formalin affected by the $\mathrm{pH}$, the influence of $\mathrm{pH}$ conditions the sample system to the intensity of reflectance sensor interaction with formalin results provide Figure 7, presented above. Based on the Figure 7, obtained information that the system for the detection of formaldehyde in the solution $\mathrm{pH}$ conditions are optimal system operating at $\mathrm{pH} 4$.

7) Sensor Selectivity

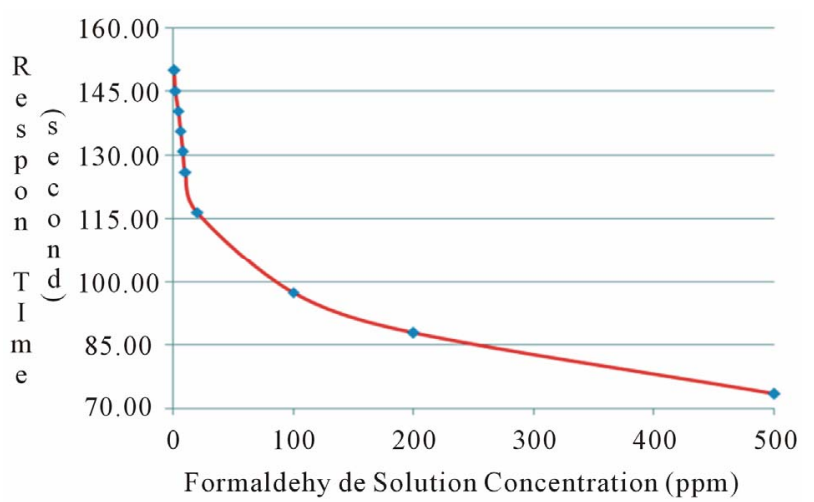

Figure 6. Response time of sensor base formaldehyde concentration.

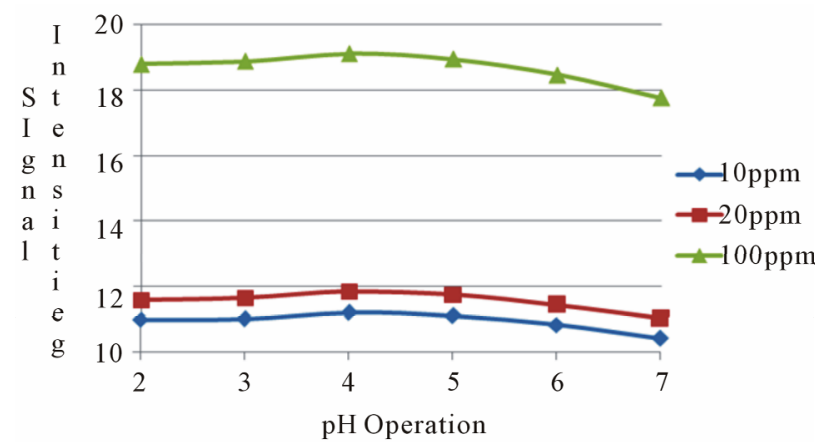

Figure 7. Effect of pH on the intensity of reflectance operational.

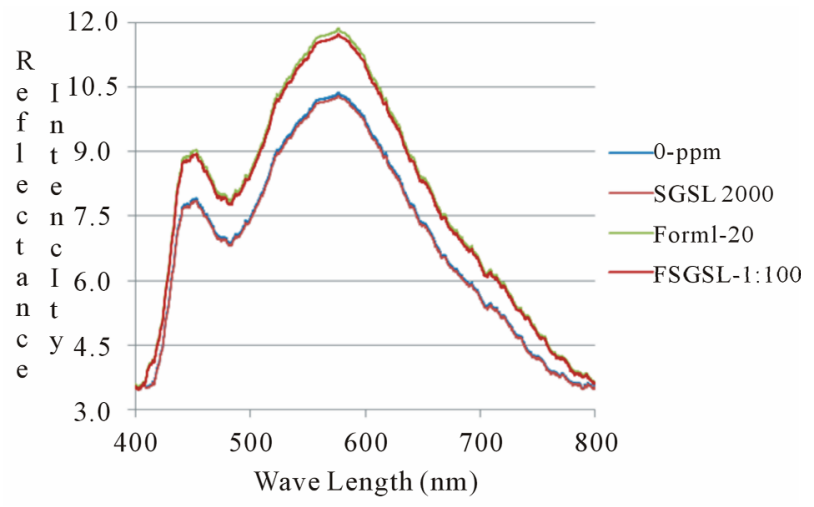

Figure 8. Sensor selectivity curve formalin to interference ratio of sugar-salt at a concentration of 1:100.

The selectivity of the sensor for the identification of formaldehyde in the system through the test solution with sugar and salt. Selectivity trials conducted with formalin concentration ratio, salt and sugar 1:10, 1:100 and 1:1000. Sample spectra pattern measurements sugar disorders and formalin shown as Figure 8 and the data as Table 4(a) the following.

According to the test result tampering sugar and salt at Table 4(a), obtained information that the existence of sugar and salt in aqueous system can provide a distrac- 
Table 4. (a): The intensity of reflectance on the condition of Interference Salt, Sugar, and Sugar-Salt Against Formalin; (b): Recovery of optical chemichal sensor on determining formalin in sample solution using standard and standard addision methode.

(a)

\begin{tabular}{|c|c|c|c|}
\hline Composition of Test Sample & \multicolumn{3}{|c|}{ Reflectance Intensity } \\
\hline 0 ppm (Blank) & 10.377 & \multirow{2}{*}{ Interferences } & \multirow{2}{*}{$\%$ Interferences } \\
\hline Formalin (F) 200 ppm & 35.354 & & \\
\hline Salt (Sl) 2000 ppm & 10.194 & \multirow{2}{*}{0.081} & \multirow{2}{*}{0.229} \\
\hline $\mathrm{F}: \mathrm{Sl}=1: 10$ & 35.273 & & \\
\hline Sugar (Sg) 2000 ppm & 10.425 & \multirow{2}{*}{0.062} & \multirow{2}{*}{0.175} \\
\hline $\mathrm{F}: \mathrm{Sg}=1: 10$ & 35.292 & & \\
\hline Sugar-Salt 2000 ppm & 10.306 & \multirow{3}{*}{0.145} & \multirow{2}{*}{0.410} \\
\hline $\mathrm{F}: \mathrm{Sg}: \mathrm{Sl}=1: 10: 10$ & 35.209 & & \\
\hline Formalin (F) 20 ppm & 11.867 & & \\
\hline Salt (Sl) 2000 ppm & 10.194 & \multirow{2}{*}{0.028} & \multirow{2}{*}{0.236} \\
\hline $\mathrm{F}: \mathrm{Sl}=1: 100$ & 11.839 & & \\
\hline Sugar (Sg) 2000 ppm & 10,425 & \multirow{2}{*}{0.100} & \multirow{2}{*}{0,843} \\
\hline $\mathrm{F}: \mathrm{Sg}=1: 100$ & 11.767 & & \\
\hline Sugar-Salt 2000 ppm & 10.306 & \multirow{3}{*}{0.126} & \multirow{2}{*}{1.062} \\
\hline $\mathrm{F}: \mathrm{Sg}: \mathrm{Sl}=1: 100: 100$ & 11.741 & & \\
\hline Formalin (F) 2 ppm & 10.547 & & \\
\hline Salt (Sl) 2000 ppm & 10.194 & \multirow{2}{*}{0.025} & \multirow{2}{*}{0.237} \\
\hline $\mathrm{F}: \mathrm{Sl}=1: 1000$ & 10.522 & & \\
\hline Sugar (Sg) 2000 ppm & 10.425 & \multirow{2}{*}{0.159} & \multirow{2}{*}{1.507} \\
\hline $\mathrm{F}: \mathrm{Sg}=1: 1000$ & 10.388 & & \\
\hline Sugar-Salt 2000 ppm & 10.306 & \multirow{2}{*}{0.181} & \multirow{2}{*}{1.716} \\
\hline $\mathrm{F}: \mathrm{Sg}: \mathrm{Sl}=1: 1000: 1000$ & 10.366 & & \\
\hline
\end{tabular}

(b)

Standard Method

Addition Method

\begin{tabular}{cccccccccc}
\hline Sample Obyek [Formalin] (ppm) [Formalin] Retrieval Std Dev Recovery (\%) & t-Test [Formalin] Retrieval Std Dev & Recovery (\%) & t-Test \\
& 10 & 9.524 & 0.299 & 95.241 & 2.755 & 9.847 & 0.171 & 98.470 & 1.552 \\
Sea Fish Meat & 20 & 19.286 & 0.353 & 96.432 & 3.498 & 19.487 & 0.303 & 97.434 & 2.932 \\
& 60 & 58.153 & 0.848 & 96.921 & 3.772 & 58.865 & 0.512 & 98.108 & 3.837 \\
& 100 & 98.636 & 0.778 & 98.636 & 3.036 & 98.379 & 0.755 & 98.379 & 3.716 \\
Noodles Soggy & 10 & 9.879 & 0,072 & 98.794 & 2.911 & 9.964 & 0.050 & 99.640 & 1.246 \\
& 20 & 19.548 & 0,265 & 97.740 & 2.959 & 19.826 & 0.153 & 99.132 & 1.969 \\
& 60 & 59.533 & 0,266 & 99.221 & 3.045 & 59.704 & 0.157 & 99.507 & 3.257 \\
\hline
\end{tabular}

tion to the measurement of the levels of formaldehyde in solution. The higher the concentration of sugar and salt, or in solution, the greater the percentage of its disorders. Selectivity of the sensor towards the sugar and salt as the interference was $1.716 \%[10,16]$.

8)Sensors Acurration

The accuracy of the sensors are tested through sensor application to a sample simulation known concentrations of formaline content. Testing using two sample object i.e. meat fish and noodles soggy, each with 4 kinds of concentration, that is $10 \mathrm{ppm}, 20 \mathrm{ppm}, 60 \mathrm{ppm}$ and 100 ppm. Testing is done through standard methods and standard addisi. The test results are shown in Table 4(b) up.
Based on the data of Table 4(b), indicating that the retrieval of chemical sensor hoses both in standard methods as well as standard addisi have trust between the area range $95.241 \%$ - 99.640\%. Test results of t-test accurasion, have been obtained a quantity t-test is smaller than the price of t-test table reference of 4.3. Such conditions mean optical chemical sensors worth applies.

9) Reuse Sensor

Test reuse (regeneration) is done by using a solution of formalin solution and blank with concentration of (10 ppm, 20 ppm, 40 ppm, 60 ppm, 80 ppm and 100 ppm). The test results give a picture of a decrease in the performance of the sensor as shown in Table 5.

Based on the data in Table 5, obtained the fact that 
optical chemical sensors can be used repeatedly for four times, because its still $92.611 \%$ compared to the initial state, means meets the minimum limit analysis method rule capabilities sensor $90 \%$ for reuse.

\section{Applications Sensor for Real Samples}

Application sensors for real samples performed using standard additions methods tested Sea-Fish meat and noodles soggy use of 5 sample objects. The results of measurements of formaldehyde content in the real sample by using optical chemical sensors and UV-Vis as a comparison method, as shown in the Table 6 below. Based on the data in Table 6 brings about reality, that the determination of formaldehyde in food samples between using the chemical sensors and methods UV-Vis provides a different quantity. But quantitatively the difference is relatively low and still meet the criteria analysis.

Table 5. Chemical sensors measure power capacity on the use in the regeneration based on the intensity of reflektan.

\begin{tabular}{cccccc}
\hline \multirow{2}{*}{ [Formalin] } & \multicolumn{5}{c}{ Reflectance intensity and sensor \% capacity } \\
\cline { 2 - 6 } & $1^{\text {st }}$ & $2^{\text {nd }}$ & $3^{\text {th }}$ & $4^{\text {th }}$ & $5^{\text {th }}$ \\
\hline \multirow{2}{*}{10} & 11.191 & 11.013 & 10.962 & 10.804 & 10.663 \\
& $100 \%$ & 98.414 & 97.958 & 96.542 & 95.284 \\
20 & 12.040 & 11.839 & 11.658 & 11.454 & 11.162 \\
& $100 \%$ & 98.331 & 96.822 & 95.126 & 92.705 \\
\multirow{2}{*}{40} & 13.856 & 13.607 & 13.266 & 12.869 & 12.260 \\
& $100 \%$ & 98.203 & 95.748 & 92.883 & 88.484 \\
60 & 15.659 & 15.264 & 14.867 & 14.183 & 13.575 \\
& $100 \%$ & 97.479 & 94.945 & 90.578 & 86.692 \\
\multirow{2}{*}{80} & 17.361 & 16.931 & 16.474 & 15.699 & 14.789 \\
& $100 \%$ & 97.520 & 94.887 & 90.427 & 85.182 \\
\multirow{2}{*}{100} & 19.064 & 18.584 & 18.063 & 17.178 & 16.130 \\
& $100 \%$ & 97.480 & 94.751 & 90.108 & 84.611 \\
Average \% capacity & 97.905 & 95.852 & 92.611 & 88.826 \\
\hline
\end{tabular}

Table 6. Formaldehyde content determination results in real sample solution by standard addition method.

\begin{tabular}{cccc}
\hline \multirow{2}{*}{ Real Sample } & $\begin{array}{c}\text { Sample } \\
\text { object }\end{array}$ & \multicolumn{2}{c}{ Real sample [Formalin] } \\
\cline { 3 - 4 } & S1 & Chemical sensor & UV-Vis \\
\hline \multirow{2}{*}{ Sea Fish } & S2 & 413.199 & 412.875 \\
Meat & S3 & 410.818 & 416.439 \\
& S4 & 419.381 & 410.783 \\
\multicolumn{1}{c}{ Average } & & 412.253 & 407.992 \\
& S5 & 414.578 & 411.753 \\
Noodles & S1 & 34.877 & 411.968 \\
Soggy & S2 & 34.753 & 34.898 \\
& S3 & 35.923 & 33.786 \\
& S4 & 36.943 & 35.253 \\
& S5 & 34.689 & 36.856 \\
Average & & 35.437 & 34.540 \\
\hline
\end{tabular}

Furthermore if the review of the results of the analysis of the paired t-tests (Paired t-Test), found no difference between the two methods of determination of the results of the two system analysis $[10,16]$.

\section{Conclusion}

Based on the test results of the operational characteristics of the optic chemical sensor fabrication yield, it can be concluded that the sensor has the feasibility to use in the process of identifying and determinating the presence of formalin in food. In addition, the sensor can be regenerated using an acid solution.

\section{Acknowledgements}

This research was funded by grants DIPA Airlangga University in 2012 according to Rector Decree No. 2613/H3.1/KR/2012 and Jember University. The autor convey thank's for assistent forman and the staffs of profusely, to the leadership and all staff LPPM UNAIR, and members of Chemo and and Biosensor group Faculty of Pharmacy UNEJ. as well as all those who helped conduct of this research.

\section{REFERENCES}

[1] Badan POM RI, "Keterangan Pers Badan POM Nomor: KH.00.01.1.241.002 Tentang Penyalahgunaan Formalin untuk Pengawet Mie Basah, Tahu dan Ikan," InfoPOM Badan Pengawas Obat dan Makanan Republik Indonesia, Vol. 7, No. 1, 2006, pp. 1-12.

[2] International Agency for Research on Cancer, "Formaldehyde, 2-Butoxy ethanol and 1-tert-Butoxypropan-2-ol," World Health Organization-Summary of Data Reported and Evaluation, Vol. 88, 2006, pp. 1-16.

[3] US Environmental Protection Agency, "Toxicological Review of Formaldehyde-Inhalation Assessment, Vol. I IV Introduction, Background and Toxicokinetics," EPA, Washington, DC, 2010.

[4] D. A. Skoog, H. Holler and Nieman, "Principles of Instrumental Analysis," 5th Edition, Saunders, New York, 2000.

[5] R. Narayanaswamy, "Optical Chemical Sensors and Biosensors for Food Safety and Security Applications," Acta Biologica Szegediensis, Vol. 50, No. 3-4, 2006, pp. 105108.

[6] B. R. Eggin, "Chemical Sensors and Biosensors," John Wiley \& Sons Inc., New York, 2002.

[7] L. Dai, P. Soundarrajan and T. Kim, "Sensors and Sensor Arrays Based on Conjugated Polymers and Carbon Nanotubes," Pure and Applied Chemistry, Vol. 74, No. 9, 2002, pp. 1753-1772. http://dx.doi.org/10.1351/pac200274091753

[8] O. Bunkoed, F. Davis, P. Kanatharana, P. Thavarungkul, and S. P. J. Higson, "Sol-Gel Based Sensor for Selective Formaldehyde Determination," Analytica Chimica Acta, 
Vol. 659, No. 1-2, 2010, pp. 251-257. http://dx.doi.org/10.1016/j.aca.2009.11.034

[9] B. Kuswandi, "Proyek Pengem-Bangan Sensor Kimia dan Biosensor Berbasis Serat Optik di Indonesia," Makalah Seminar Kimia FMIPA UNEJ, Universitas Jember, Jember, 2001

[10] M. M. Collision and A. R. Howels, "Chemical Sensor," Analytical Chemistry, Vol. 39, 2000, pp. 600-618.

[11] C. C. Perry, "Sol-Gel Technology the Way Forward for Tomorrow's Material," Trent University, Nottingham, 1996.

[12] R. R. Miksch, W. A. Douglas, Z. F. Leah, D. H. Craig, R. Kenneth, G. Jacquelline, "Modified Pararosaniline Method for the Determination of Formaldehyde in Air,"
Analytical Chemistry, Vol. 53, No. 13, 1981, pp. 21182123. http://dx.doi.org/10.1021/ac00,236a040

[13] L. Dai, P. Soundarrajan and T. Kim, "Sensors and Sensor Arrays Based on Conjugated Polymers and Carbon Nanotubes," Pure and Applied Chemistry, Vol. 74, No. 9, 2002, pp. 1753-1772. http://dx.doi.org/10.1351/pac200274091753

[14] G. J. Mohr, "Materials and Polymers in Optical Sensing," Institute of Physical Chemistry, FSU-Jena, 2002.

[15] IUPAC, "Selectivity in Analytical Chemistry (IUPAC Recommendations 2000)," 2001.

[16] J. C. Miller and J. N. Miller, "Statistics for Analytical Chemistry," Ellis Horward, PTR, Tentice Hall, England, 1993. 